\title{
Insight on the Ultrastructure, Physicochemical, Thermal Characteristics and Applications of Palm Kernel Shells
}

\author{
Richard Ntenga ${ }^{1,2 *}$, Etienne Mfoumou ${ }^{3}$, Alexis Béakou ${ }^{4}$, Martin Tango ${ }^{5}$, Jordan Kamga ${ }^{3}$, \\ Ali Ahmed² \\ ${ }^{1}$ Laboratoire de Mécanique et Productique (LMP), UFD SI, Université de Douala, Douala, Cameroun \\ ${ }^{2}$ Laboratoire d'Analyse, Simulations et Essais (LASE), IUT, Université de Ngaoundéré, Ngaoundéré, Cameroun \\ ${ }^{3}$ Applied Research \& Innovation, Nova Scotia Community College, Dartmouth, Canada \\ ${ }^{4}$ Institut Pascal UMR 6602-UCA-CNRS-SIGMA, Clermont-Ferrand, France \\ ${ }^{5}$ Ivan Curry School of Engineering, Acadia University, Wolfville, Canada \\ Email: ^rntenga@gmail.com, richard.ntenga@univ-ndere.cm
}

How to cite this paper: Ntenga, R., Mfoumou, E., Béakou, A., Tango, M., Kamga, J. and Ahmed, A. (2018) Insight on the Ultrastructure, Physicochemical, Thermal Characteristics and Applications of Palm Kernel Shells. Materials Sciences and Applications, 9, 790-811.

https://doi.org/10.4236/msa.2018.910057

Received: July 25, 2018

Accepted: September 3, 2018

Published: September 6, 2018

Copyright $\odot 2018$ by authors and Scientific Research Publishing Inc. This work is licensed under the Creative Commons Attribution International License (CC BY 4.0).

http://creativecommons.org/licenses/by/4.0/

\begin{abstract}
The ultrastructure and physicochemical and thermal properties of Palm Kernel Shells (PKS) in comparison with Coconut Kernel Shells (CKS) were investigated herein. Powder samples were prepared and characterized using Surface Electron Microscopy (SEM) and Transmission Electron Microscopy (TEM). Chemical and elemental constituents, as well as thermal performance were assessed by Van Soest Method, TEM/EDXA and SEM/EDS techniques. Differential Scanning Calorimetry (DSC) and Thermogravimetric Analysis (TGA) were also performed for thermal characterization. SEM/EDS and TEM/EDXA revealed that most of the PKS and CKS materials are composed of particles with irregular morphology; these are mainly amorphous phases of carbon/oxygen with small amounts of $\mathrm{K}, \mathrm{Ca}$ and $\mathrm{Mg}$. The DSC data permitted to derive the materials' thermal transition phases and the relevant characteristic temperatures and physical properties. Thermal Transition phases of PKS observed herein are consistent with the chemical composition obtained and are similar to those of CKS. Nonetheless, TGA/DTG showed that the combustion characteristics of PKS are higher than those of CKS. Taken together, our results reveal that PKS have nanopores and can be efficiently used for 3D printing and membrane filtration applications. Moreover, the chemical constituents found in PKS samples are in agreement with those reported in the literature for material structural applications and thus, present potential use of PKS in these applications.
\end{abstract}

\section{Keywords}

Biomass Materials, Palm Kernel Shell, SEM \& TEM Ultrastructure, Thermal 
Properties, Physico-Chemical Properties

\section{Introduction}

Ensuring economic sustainability in developing countries has led to harnessing biomass materials having potential value added applications [1] [2] [3]. In this context, Palm Kernel Shells (PKS) that are agricultural solid end products of oil palm manufacturing processes show promising features for novel applications. The Palm Oil Plant (Elaeis Guineesis jacq.) exists in three different cultivars namely Dura, Pisiphera and Tenera [4] [5]. The wild occurring cultivar, Dura, produces a fruit with a thick kernel shell, whereas the Pisiphera cultivar is devoid of shell and the Tenera hybrid cultivar is obtained by crossbreeding Dura and Pisiphera. The Tenera species, with its thin kernel shell and abundant pulp, is the most industrially exploited and therefore the main waste material targeted herein. The literature reports around half a ton of PKS for every ton of palm oil produced from fresh fruit bunches [6]. In this context, the use of this agro industrial waste as potential source of raw materials for engineering applications has gained greater interest today as never before. This has been justified by the unique properties of these materials, originating from their ligno-cellulosic nature as well as their hierarchical organization [7] [8] [9] [10].

There has been a long-standing interest to using PKS in various engineering applications. Herawan et al. [11] carried out the characterization of Activated Carbon produced from PKS (AC-PKS); nitrogen adsorption at $77 \mathrm{~K}$ was employed to verify the effect of the pore structure on the adsorption properties. They observed a significant improvement in the surface characteristics of the activated carbons. Using potassium carbonate $\left(\mathrm{K}_{2} \mathrm{CO}_{3}\right)$ as activating agent, Adinnata et al. [12] reported the influence of carbonization temperatures on the pore development and yield in the AC-PKS. They found that by increasing the carbonization temperature and impregnation ratio, the yield decreases, while the adsorption of $\mathrm{CO}_{2}$ increases, progressively. Guo et al. [13] [14] showed that the adsorptive capacities of the PKS adsorbents can be improved by surface functional groups that reacts with nitrogen dioxide $\left(\mathrm{NO}_{2}\right)$ and ammonia $\left(\mathrm{NH}_{3}\right)$ gases. They also proposed methods of chemical activation of PKS using Phosphoric acid $\left(\mathrm{H}_{3} \mathrm{PO}_{4}\right)$ and Potassium Hydroxide $(\mathrm{KOH})$.

Considering the increasing interest of microwave pyrolysis [15] [16], Ani and Salema [17] investigated the heating characteristics of PKS char prior to using it as microwave absorber during the pyrolysis of oil palm biomass [17]. They found that PKS char has a significant influence on the product yield and can reduce the energy consumption, time and cost of the thermo-chemical process. The liquid obtained from the PKS pyrolysis was reported to contain a high concentration of phenol and its derivatives [18]. These are viewed as high value chemicals with diverse applications. Phenol can indeed be used to manufacture 
molding products for automotive parts, household appliances and electrical components; phenol can also be used in bonding and adhesive resins for laminating, plywood, protective coating, insulation materials and abrasive coating, as well as in foundry industries for sand molds and cores [19]. Therefore, extracting phenol during PKS pyrolysis could present high advantages, since petroleum-based phenol is rather expensive.

Sabzoi et al. [20] performed a parameters' optimization study during the catalytic hydrolysis of PKS for bio-oil production. The optimization parameters were reaction temperature, reaction time and sodium hydroxide $(\mathrm{NaOH})$ concentration. The $\mathrm{NaOH}$ concentration was observed as the most influencing parameter in liquid yield because of cracking of reaction or reduction of reaction taking place during the hydrolysis process with $\mathrm{NaOH}$.

Due to its higher content of silica $\left(\mathrm{SiO}_{2}\right)$ and higher powder fineness, PKS Ash (PKSA) was recently used as binder and coarse aggregate in geopolymer concrete and concrete formulation [1] [3] [21] [22] [23] [24]. The mechanical properties of the obtained PKS-based concrete and PKSA-based geopolymer structural lightweight concrete were investigated and reported. These properties included the slump density, compressive strength, splitting tensile strength, flexural strength, and modulus of elasticity under various operating curing conditions. Ofuyatan et al. [25] carried out a study on the durability (tested by acid resistance, sulphate attack) of Self Compacting Concrete with partial placement of Portland cement by PKSA. This research on the durability of self-compacting concrete, had focused on the freeze/thaw resistance and the chloride penetration. The authors reported that the concrete properties are enhanced with the increase of ash content. Fono-Tamo et al. [26] found that PKS and sand dust could be advantageously mixed to fabricate standard particleboards. Magniont and Escadeillas [27] presented a review on the chemical composition of bio-aggregates resources used as building materials; they focused on various plant aggregates other than plant fruit kernel shells. While it is particularly important to note that the unique properties of these materials originate from their structural composite nature [28], Singh et al. [29] reported the use TGA derivedpyrolytic unit thermograms to predict the percentage of chemicals in biomassviewed as mixtures. Pang et al. [7] established the relationship between biomass thermal behavior and its lignocellulosic composition. Likewise, thermal behaviors and properties of these chemicals have been studied by several other researchers [30] [31] [32]. Recently, Ninduangdee et al. [33] used TGA to investigate the degradation behavior and the combustion characteristics of PKS. They evaluated their activation energy as well as their ignition, burnout and other phase transitions temperatures. Some physico-chemical characteristics of PKS were also reported in reference [33] with no indication on their source. Moreover, the pyrolysis TGA-characteristics of PKS were reported by Ma et al. [34] with two significant mass-loss ascribed solely to hemicelluloses and lignin.

However, despite the high growing interest on the PKS, its physicochemical 
and thermal characterization as an engineering raw material has received limited attention over the past decades, while the production for this agroindustrial waste has increased worldwide. Multiple other PKS value added and engineering applications could therefore be further explored, such as energy production, ceramics [35] [36], composites [37] [38] [39] [40], sintering, membrane filtration, phase change wall materials or 3D printable biomaterials [41] [42] from vegetal powders. Hence, this research work addresses the determination of microstructure, thermal and physico-chemical properties of PKS and CKS, for industrial applications. CKS, which is a tropical fruit kernel shell of the coconut tree, hasbeen investigated in previous studies [38] [43], and introduced here fora comparison purpose.

\section{Experimental}

\subsection{PKS and CKS Materials}

PKS Tenera waste was obtained from Mbambou Palm Oil Mills of Socapalm Land Development Authority, Dizangué Sub-Division in the littoral region of Cameroon, while PKS Dura waste was collected from the Institute of Agricultural Research for Development (IRAD) of Mbongo. The shells were washed using a sodium hydroxide solution, rinsed by demineralised water and dried in an oven at $70^{\circ} \mathrm{C}$ during $48 \mathrm{~h}$, prior to analyses. Whereas, CKS waste was collected from local coconut commercial garbage zones at Missole and underwent the same preparation. The shells were grounded and sieved. Powders obtained are from different sizes varying from $0.04 \mathrm{~mm}$ to $0.5 \mathrm{~mm}$, in addition weighted.

\subsection{Density of PKS}

The well-established pycnometers measuring technique was used. The density of PKS is given by:

$$
\left(d_{\mathrm{PKS}}\right)_{E}=\frac{m_{1}-m_{2}}{\left(m_{3}-m_{1}\right)\left(m_{4}-m_{2}\right)} d_{s}
$$

where $d_{s}$ is the density of solvent, $m_{1}$ represents the mass of the empty pycnometer, $m_{2}$ the mass of the pycnometer filled with PKS powder, $m_{3}$ the mass of the pycnometer filled with the immersion fluid, and $m_{4}$ the mass of the pycnometer filled with the immersion fluid and PKS powder.

The value obtained was compared to that of the simple Rule of Mixture (ROM) density produced as:

$$
\left(d_{\mathrm{PKS}}\right)_{R O M} \approx \frac{1}{\left(\frac{w_{L}}{d_{L}}+\frac{w_{H C}}{d_{H C}}+\frac{w_{C}}{d_{C}}\right)}
$$

where, $w_{L}, w_{C}$ and $w_{H C}$ stand for mass fractions of Lignin, Cellulose and Hemicelluloses, respectively and are to be obtained herein by wet chemistry analysis; $d_{L}$, $d_{C}$ and $d_{H C}$ are used for densities of Lignin, Cellulose and Hemicelluloses respec- 
tively, and values of these chemicals were obtained from the literature [28] [44].

\subsection{SEM/EDS Analysis}

For SEM observations, the PKS/CKS powders were spread onto an aluminum stub covered with a conductive carbon tape, such that the powder was evenly distributed on the surface of the carbon tape. The samples were coated with a mixture of gold and palladium by a sputter coater (Polaron SC 7640). All powders were brown. PKS sample was the roughest, and CKS was the finest by naked eyes.

A JEOL JSM-6900 Low Vacuum SEM was used to observe the surface morphologies of the products. It is a high-performance scanning electron microscope for fast characterization and imaging of fine structures on both small and large samples. Energy Dispersive Spectroscopy (EDS) for qualitative analysis of the sample elements was performed by using the Integrated Microanalyzer for images and X-rays (IMIX) system.

\subsection{TEM/EDXA Analysis}

Likewise, for TEM/EDS, the as-received PKS/CKS powders were crushed with an agate mortar and pestle under distilled water to reduce the particle size. TEM specimens were made with the ground powder as follows: powder was sonicated for 5 minutes in distilled water then dropped onto a lacey carbon coated grid.

For the ultrastructure characterization, a JEOL TEM, with a JSX-1000S Fluorescence Spectrometer X-ray analyzer was used. It is also an elemental analysis tool, capable of identifying the elements in areas less than $0.5 \mu \mathrm{m}$ in diameter from carbon to uranium.

\subsection{Chemical Constituents}

The PKS (Tenera and Dura) powders were used in this study. Cellulose, hemicelluloses and lignin contents were firstly investigated, as lignocellulosic raw resources main structural chemical components. The well-known and widely accepted Van Soest Method (NDF and ADF analyses) [45] [46] [47], was used to determine cellulose $\left(w_{C}\right)$, hemicelluloses $\left(w_{H C}\right)$, lignin $\left(w_{L}\right)$ and mineral matter $\left(w_{M M}\right)$ contents in PKS. A Perkin Elmer CHNO/S Analyzer 2400 enabling the implementation of the TAPPI analysis was used [12]. PKS powders were treated with a Neutral Detergent Solution (NDS solution) for the NDF fraction $(C, L$, $H C$ and $M M_{n}$ ) and an Acid Detergent Solution (ADS solution) for the ADF fraction $\left(C, L, M M_{a}\right)$. The powders were filtered using a sintered glass pan and their remaining residues dried at $60^{\circ} \mathrm{C}$ during $48 \mathrm{hrs}$. Van Soest NDF method measures most of the structural components in plant cells (i.e. lignin, hemicelluloses and cellulose), but not pectin. The ADF residue consists of cellulose, lignin, cutin, and acid-insoluble ash (mainly silica).

\subsection{DSC and TGA Analysis}

Samples for DSC analysis were prepared by adding the desired amount of the 
as-received PKS (Tenera and Dura) and CKS powders (ca. $8 \mathrm{mg}$ ) to a tared DSC pan. After recording the mass, the pan and lid were crimped and the sample sealed within the space. Hermetically sealing (crimping) the pan is done to reduce the temperature gradient within the pan. For TG analysis, the alumina $\left(\mathrm{Al}_{2} \mathrm{O}_{3}\right)$ sample cups are tarred in the instrument and the desired sample is added to the sample cup. Since the sensitivity of the TGA instrument is on the microgram scale, sample sizes need only be ca. $1 \mathrm{mg}$ or less. The furnace is closed and the software logs the sample mass as time/temperature increase. Thermal characteristics were evaluated using DSC measurements via a TA instruments Q200 V24.11 Build 124 model DSC. Measurements were performed in the temperature regime of ambient to $500^{\circ} \mathrm{C}$ under a nitrogen atmosphere (flow rate of $50 \mathrm{~mL} \cdot \mathrm{min}^{-1}$ ) using the forced air cooling accessory as the cooling unit. The cell is calibrated with an Indium standard reference material (melting point $156.6^{\circ} \mathrm{C}$ and an enthalpy of $28.71 \mathrm{~J} \cdot \mathrm{g}^{-1}$ ) prior to samples being run. A second temperature reference is also used at $327.5^{\circ} \mathrm{C}$. In addition, TGA measurements were conducted on a TA instruments SDT-Q600 V20.9 Build 20 model TG. Measurements were performed in the temperature regime of ambient to $600^{\circ} \mathrm{C}$ under argon (flow rate of $50 \mathrm{~mL} \cdot \mathrm{min}^{-1}$ ). The TG SDT-Q600 is controlled by proprietary thermal software, and has auto-sampler accessories for unattended operation. The mass of the specimens was monitored as a function of temperature or time. The TGA and DTGA served to determine the residue, moisture and volatiles [34] contents as well as the mass loss of each material major chemical, from where chemical contents were deduced. The following characteristics could then be investigated.

\subsubsection{Melt and Glass Transition Temperatures}

The endotherm of melting corresponds to the portion of the DSC curve that is far from the baseline, and, later, returns to it. The melting temperature, $T_{\text {onsen }}$ is defined by the extrapolated beginning of the curve, being defined by the point of intersection of the tangent with the point of maximum slope, on the principal side of the peak with the base line extrapolated. The melting temperature value $T_{m}$ from the endothermic and the corresponding heat flow latent (calorific value) $H_{m}$ are readily obtained on the DSC thermogram. From the DSC thermogram glass transition temperature, $T_{g}$ can be derived. For, the glass transition is a second order transition. $T_{g}$ is manifested by a sudden increase in the base line, indicating an increase in the heat capacity of the polymer probably after water and volatiles total evaporation and decomposition.

\subsubsection{Specific Heat Capacity}

The thermal step-height of the heat capacity $\Delta C_{p}$ of the samples is to be evaluated at glass transition temperature. The heat capacity $C_{p}$ is defined by:

$$
\Delta C_{p}=\Delta \frac{d H}{d T}=\Delta \frac{d H}{d t} \frac{d t}{d T}
$$

where, represents the temperature scan rate. The difference in the heat capacity of the sample and the reference is defined as in Equations (4) and (5): 


$$
\begin{aligned}
\Delta C_{p} & =C_{\text {psample }}-C_{\text {preference }} \\
C_{\text {psample }} & =\Delta \frac{d H}{d t} \frac{d t}{d T}+C_{\text {preference }}
\end{aligned}
$$

where, $\Delta \frac{d H}{d t}$ is the shift in the baseline of the thermogram. Equation (5) is readily derived from Equation (3). Hence, at glass transition, $C_{p}$ is given by:

$$
C_{\text {psample }}=\Delta \frac{d H}{d t} \frac{d t}{d T}+C_{\text {preference }}
$$

\subsubsection{Thermal Conductivity}

The thermal conductivity, $k$ and thermal diffusivity coefficient $a$, are given by

$$
\frac{k}{C_{p} \cdot d}=a
$$

where, $d$ is the density of the tested material. The value of $k$ obtained by means of direct ROM from the known $k$-values $\left(k_{C}=0.40, k_{L}=0.35-0.279, k_{H C}=\right.$ $0.38 \mathrm{~W} \cdot \mathrm{m}^{-1} \cdot \mathrm{K}^{-1}$ ) [31] [44] [48] of Lignin, Cellulose and Hemicelluloses. a-values of PKS/CKS are calculated using Equation (7).

\section{Results and Discussion}

\subsection{SEM and TEM Morphology and Physical Properties}

\subsubsection{SEM and EDS}

Figure 1 and Figure 2 show the SEM micrographs of PKS and (Figure 3 ) that of CKS. The particles are irregular in shape and size as illustrated in Figure 1(a), Figure 2(c), Figure 3(a) and Figure 3(b). Figures 1(d)-(f), Figure 2(a) and Figure 2(b), Figure 2(b) and Figure 3(g) are of higher magnification and show the plant cell/tissue structures of microporous [49] particles. The PKS material could therefore be efficiently used for membrane filtration applications. The images taken by SEM are two dimensional and it is impossible to measure the particles volume accurately under our current conditions. However, the length of particles was measured as illustrated in Figure 2(c). Statistical data showed that PKS particles had a mean length of $551.8 \mu \mathrm{m}(\mathrm{n}=109, \mathrm{sd}=186.1 \mu \mathrm{m})$ and CKS: $X=251.8 \mu \mathrm{m}(\mathrm{n}=94$, sd $=95.3)$. Figure $2(\mathrm{~d})$ presents an $X$-ray spectrum of elemental-analysis by EDS. The elements are mainly carbon and oxygen. A display of the cross-point whereby the EDS spot analysis was performed is shown on the figure. The spectrum of EDS shows that the sample contained carbon and oxygen (as main elements) as well as some silicon.

Morphologically, CKS appears similar to PKS. CKS particles have very clear plant cell/tissue structures. Figure 3(a) and Figure 3(b) show an overview of the CKS particles indicating the irregularity in shape and size. Figure $3(c)$ and Figure $3(d)$ are showing the cell and tissue structures of the particles. Figures $3(\mathrm{e})-(\mathrm{h})$ are showing the ultrastructure of the particles, which are typical plant-like cell and tissue structures. 


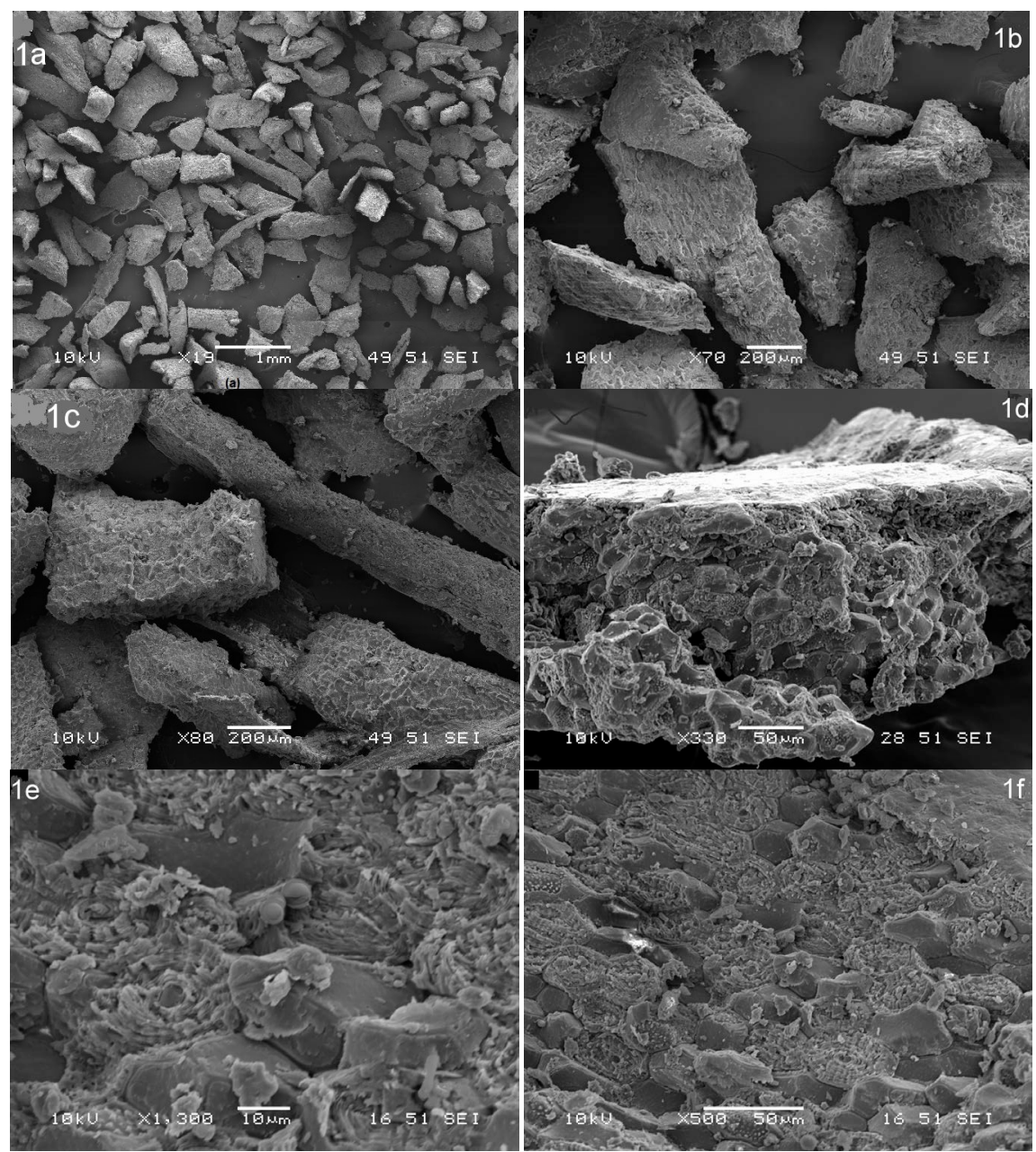

Figure 1. SEM micrographs of PKS (a) particle shapes of the powder (b), (c) \& (d) cake-like poorly compacted particle structure (e) \& (f) distinct material constituents.
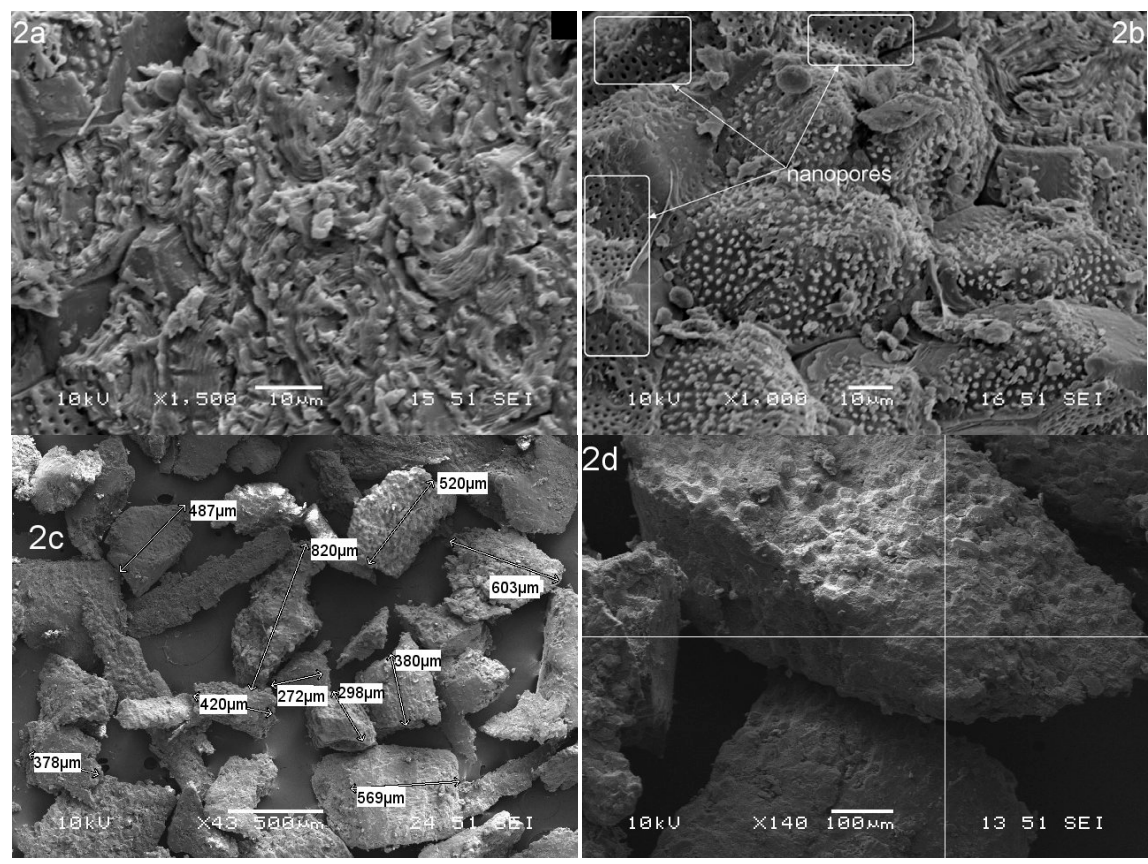


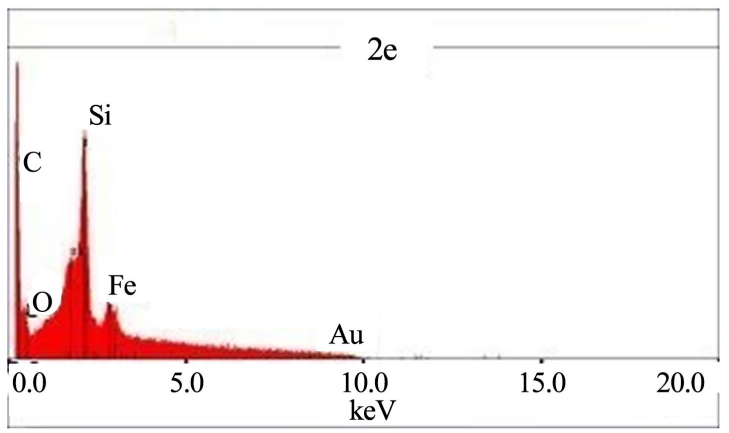

Figure 2. SEM micrographs of PKS (a) \& (b) Microporous microstructure (c) Particle sizes (d) EDS aperture (e) EDS spectrum of particle in Figure 3(d).
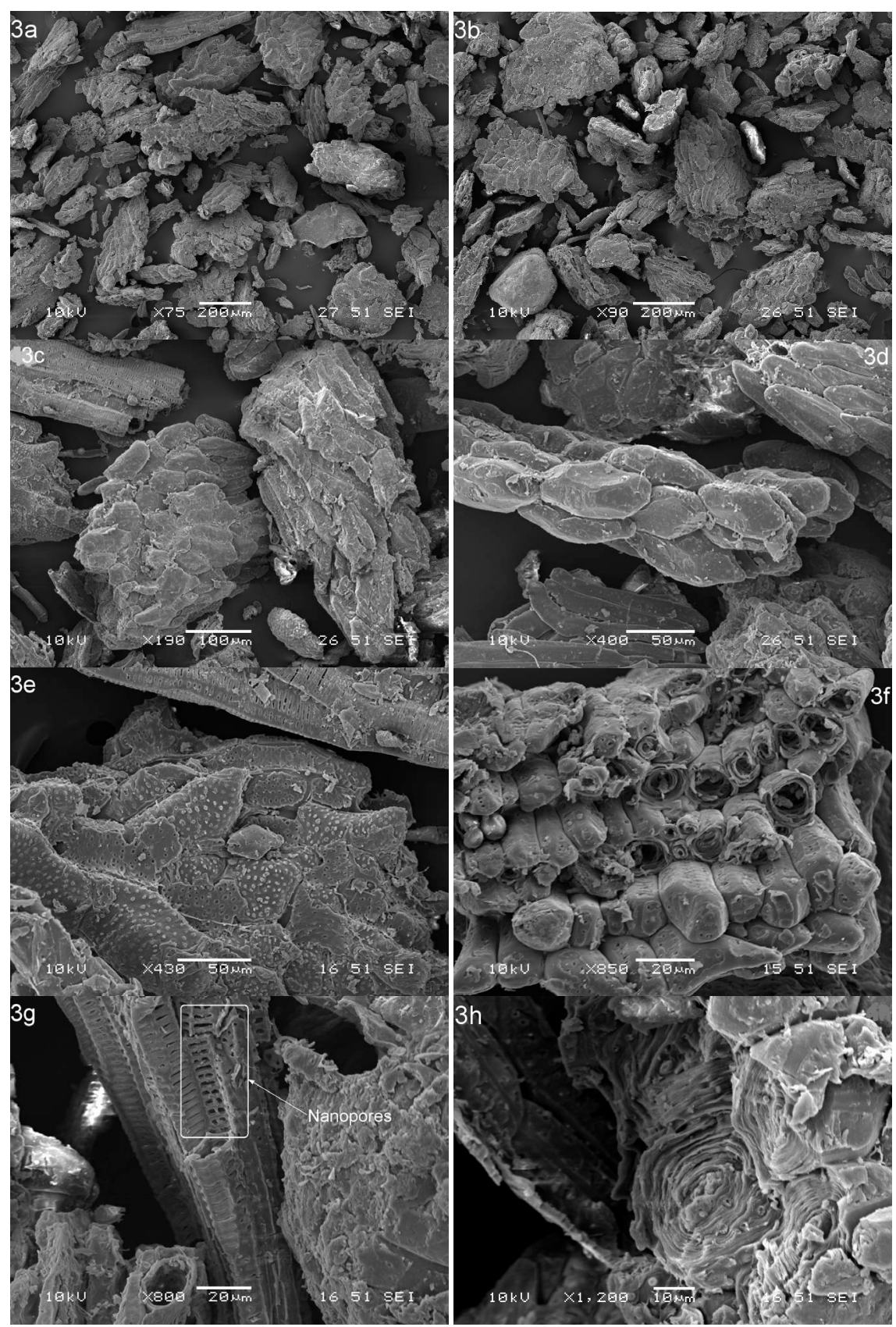


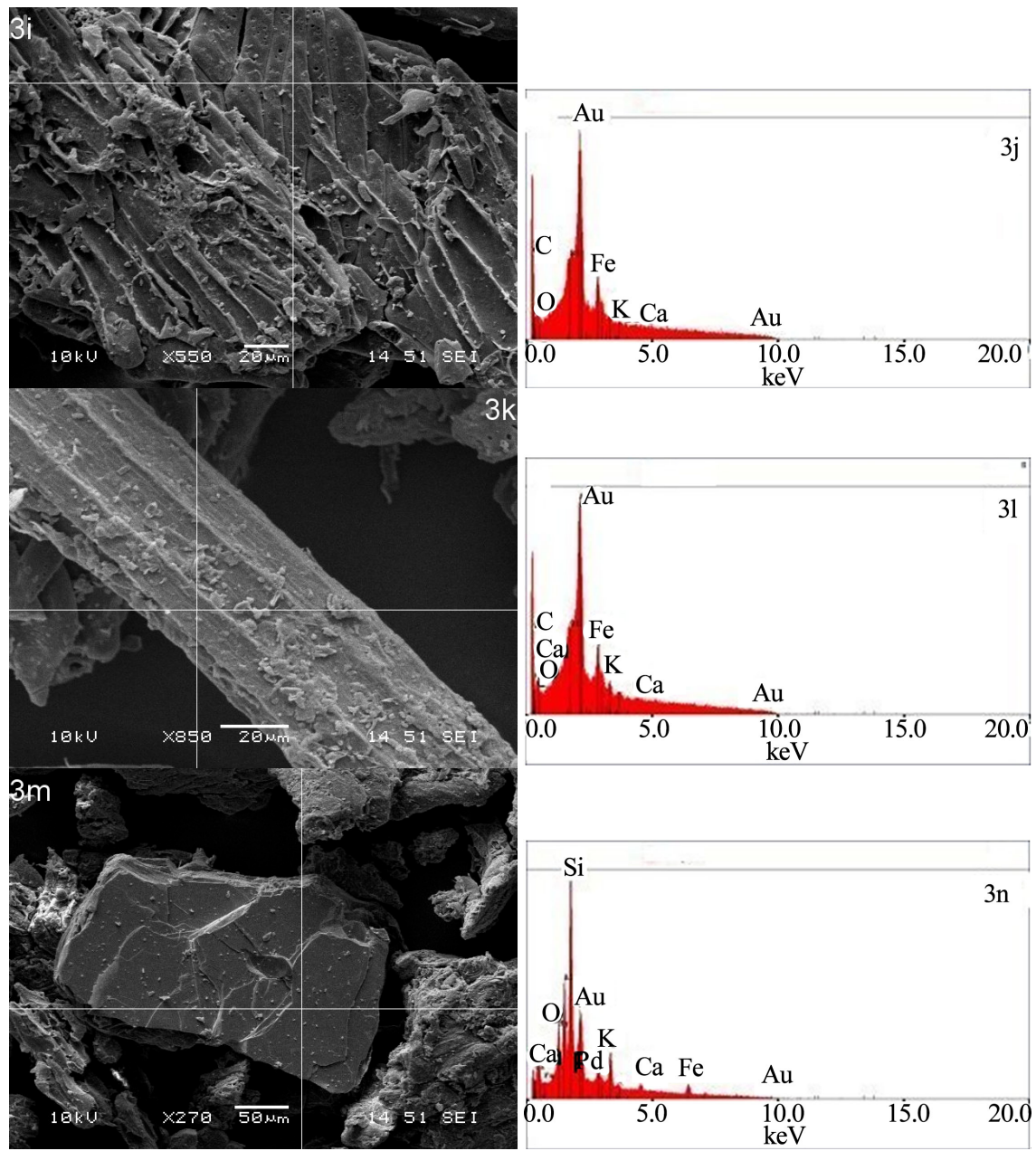

Figure 3. SEM micrographs of CKS (a) \& (b) Particle shapes of the powder (c), (d) \& (f) Aggregate agglomerated microstructure (e), (g) \& (h) Microporous microstructure (i), (k) \& (m) EDS apertures (j), (l) \& (n) EDS spectra of particles in Figure 3(i), Figure 3(k) \& Figure 3(m).

EDS data of CKS plant cell/tissue show a composition similar to those of PKS, containing $\mathrm{C}, \mathrm{O}$ and silicon (Figures 3(i)-(1)). Occasionally, some rock-like particles were observed and EDS analysis showed that they mainly contain silicon. $\mathrm{Al}, \mathrm{K}, \mathrm{Ca}, \mathrm{Fe}, \mathrm{Mg}, \mathrm{C}$ and $\mathrm{O}$ were also detected in the rock-like particles (Figure $3(\mathrm{~m})$ and Figure $3(\mathrm{n}))$.

\subsubsection{TEM Ultrastructure and EDX Analysis}

Representative micrographs are shown in Figure 4. Figure 4(a) (BF 4900x) shows a typical morphology of a particle (particle 1 here) with irregular, somewhat layered shape but with inhomogeneity. Typical X-ray microanalysis (Figure 4(b)) of such particles gives mainly carbon and oxygen, but small amounts of $\mathrm{Ca}$ and $\mathrm{K}$ are also present. In some cases (as here where a large probe was used to sample most of the particles), $\mathrm{Si}, \mathrm{Al}$ and $\mathrm{Fe}$ are also detected; the proportion of these elements is inconsistent, so their presence is likely associated 
with separate sources (e.g. silicon oxide, iron oxide and aluminum oxide). Here, $\mathrm{Cu}$ originates from the support grid. Figure 4(c), an electron diffraction pattern with selected area aperture on most of particle 1, shows weak rings typical of amorphous carbon plus weak diffraction spots displayed in rings which are related to a crystalline phase/phases; this may be associated with $\mathrm{Al} / \mathrm{Fe} / \mathrm{Si}$ oxides. Figure 4(d) (BF 12X) shows dark, crystalline particles in carbon matrix.

Figure 5 presents TEM micrographs of PKS. In Figure 5(a) (011 BF 7400× particle 3), a typical majority phase of particle 3 is shown. A Selected Area Electron Diffraction Pattern (SAEDP) is typical to amorphous carbon. EDS spectrum is similar to that shown previously (Figure $4(\mathrm{~b})$, mainly made up of carbon and oxygen with some $\mathrm{Ca}$ and $\mathrm{K}$ peaks. Figure 5 (b) (BF 10,500x) of particle 2 represents a typical secondary phase found with a plant-like cell wall morphology. A SAEDP from left hand corner of particle 2 (Figure 5(c)) shows that the material is crystalline. This pattern can be indexed as [001] zone axis of Beta-quartz (hex, $a=0.491 \mathrm{~nm}$ and $c=0.540 \mathrm{~nm}$ ). Figure $5(\mathrm{~d}$ ) is an EDS spectrum from particle 2 and is consistent with the identification as quartz (silicon oxide). In Figure 5(e), it is observed that most of particle 5 is the majority phase mainly composed of amorphous carbon and oxygen. The top right area (dark contrast, arrowed) is a secondary phase. Figure 5(f) shows an EDS spectrum from the dark region of particle 5. A SAEDP from dark region of particle 5 is similar to that of particle 2, but exhibiting some disorder. Figure 5(g) from particle 6 is an amorphous majority phase, EDS mainly gives carbon and oxygen with some Ca and $\mathrm{K}$.

To sum up, most of the PKS material is composed of microporous particles with very irregular morphology. These particles are mainly amorphous phases of carbon/oxygen with small amounts of $\mathrm{Ca}$ and $\mathrm{K}$. Secondary phases, mainly silicon oxides, could be contaminants, some of which may be sand. Also detected are various other materials in small amounts such as graphite.

The majority phase and an X-ray spectrum of a CKS particle are shown in Figure 6(a) and Figure 6(b) respectively. Many similar large particles were found. The particle shown is noncrystalline, however the particles are crystalline, composed of single crystals. X-ray microanalysis gives silicon and oxygen. Another crystalline oxide particle was found and contained a large amount of silicon as well as calcium and aluminum. Electron diffraction patterns are consistent with quartz (crystalline) and sometimes polycrystalline. As noted with SEM micrographs, TEM shows that the CKS material is morphologically identical to the PKS. However, for CKS, there is a large amount of secondary phases or contaminants, including large particles of quartz (silicon oxide) as well as agglomerations of small crystalline particles, which are composed of $\mathrm{Fe}, \mathrm{Al}, \mathrm{Si}$ and O. Again, X-ray microanalysis performed on TEM sample nano-locations are almost consistent with that performed on SEM sample micro-locations. The detection of $\mathrm{Ca}, \mathrm{P}, \mathrm{Mg}$ and $\mathrm{O}$ as well as the presence of micropores, justify the empirical use of PKS in sanitation and purification. Micropores also foster its applicability in membrane filtration. 


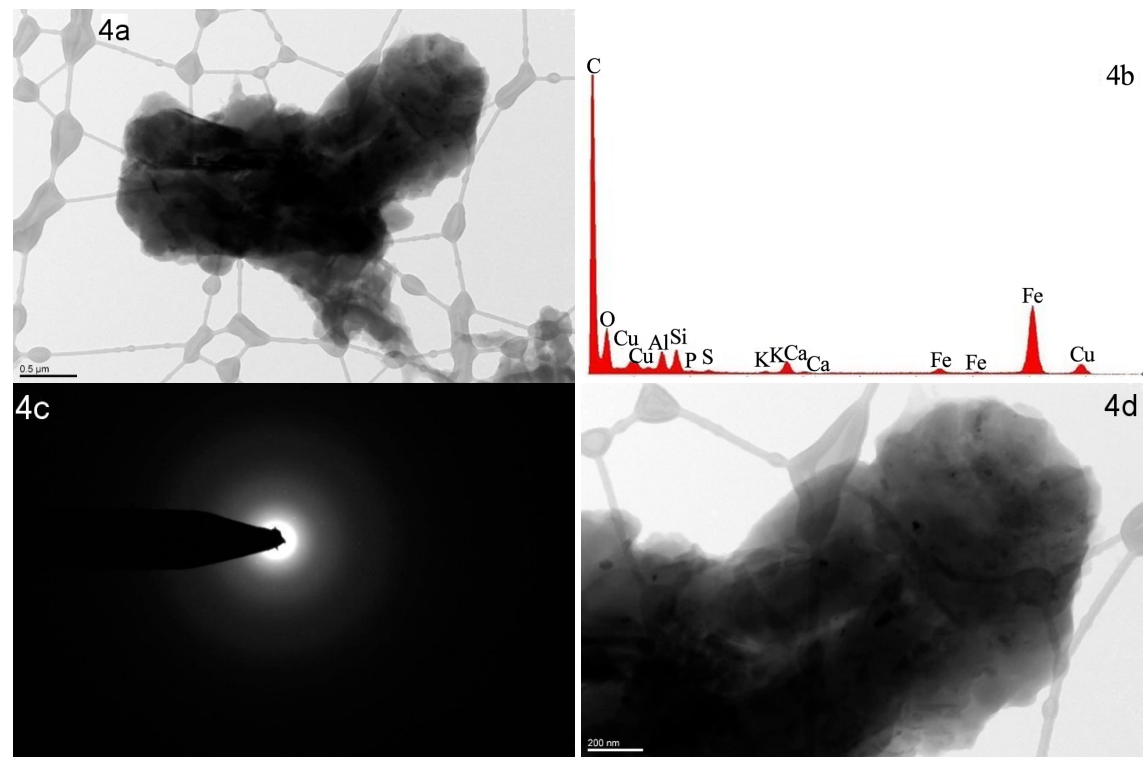

Figure 4. TEM micrographs of PKS particle 1 (a) particle majority phase (b) particle EDX spectrum (c) EDX spot (d) dark, crystalline particles in carbon matrix.
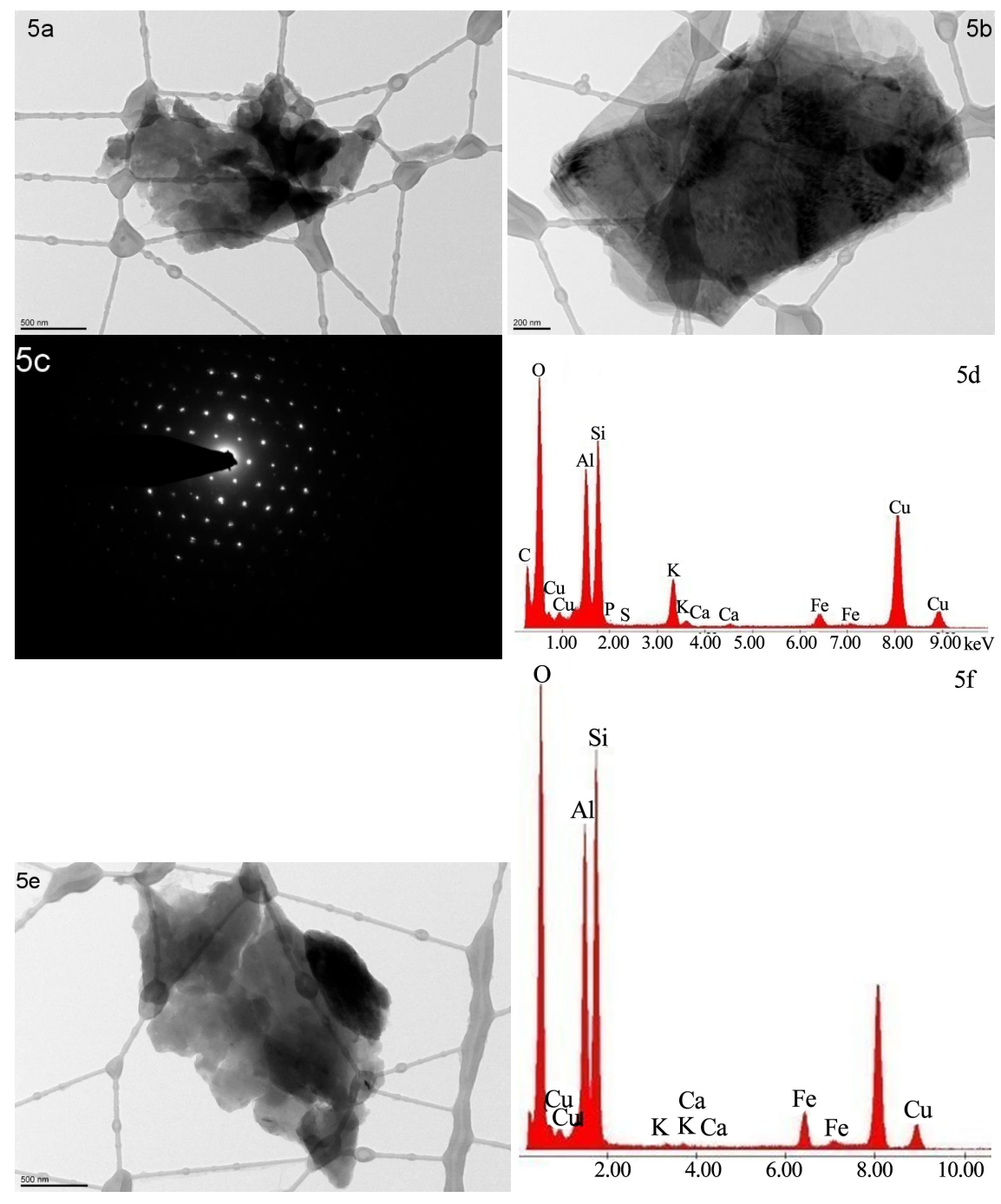


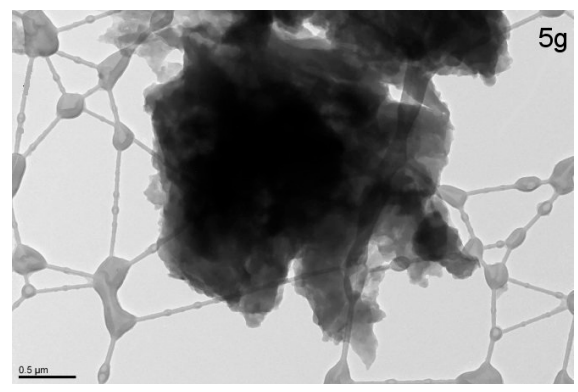

Figure 5. TEM micrographs of PKS (a) 7400× particle 3, typical majority phase (b) Typical representative of a secondary phase of particle 2 (c) SAEDP with aperture on the middle of particle 2 (d) EDS spectrum from particle 2 (e) Particle 5 majority phase (f) EDS spectrum from the dark region of particle $5(\mathrm{~g})$ Amorphous majority phase.
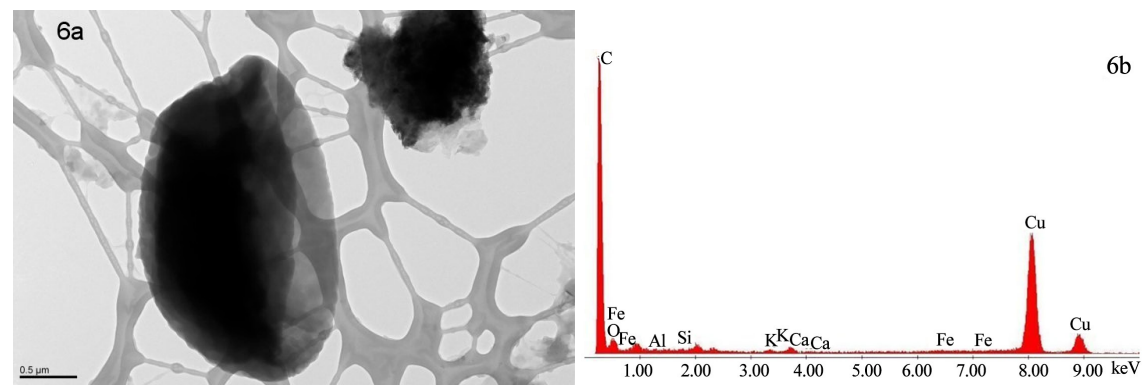

Figure 6. TEM micrographs of CKS (a) 5600×, a noncrystalline nanoparticle (b) X-ray spectrum of the particle in Figure 7.

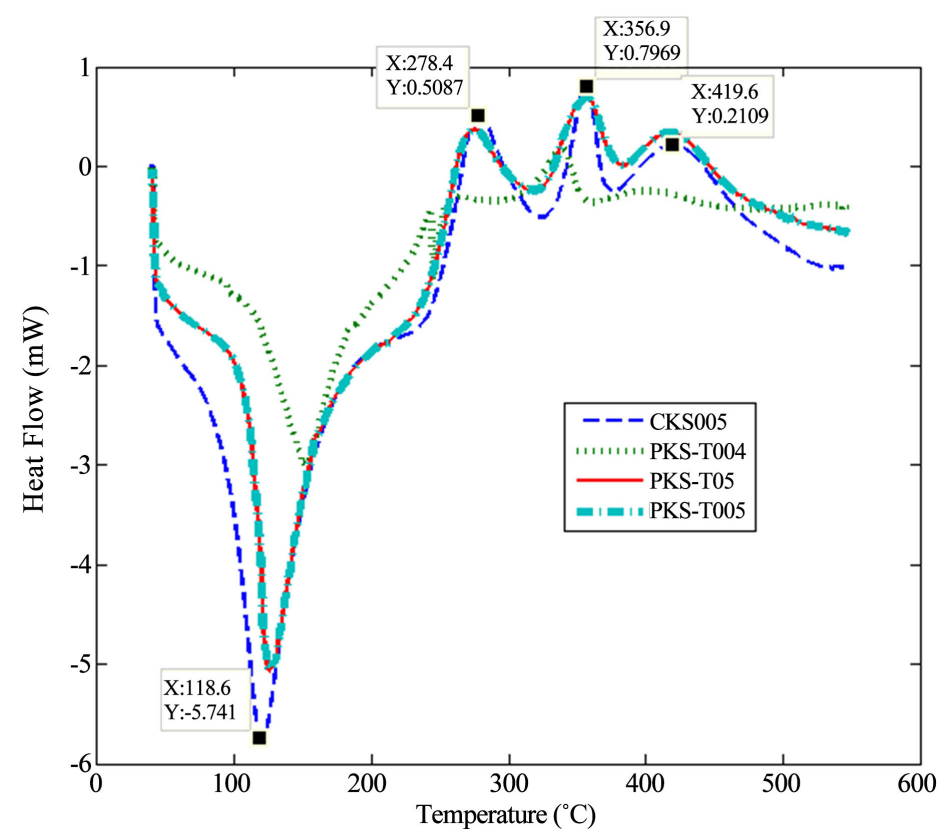

Figure 7. CKS \& PKS Combined DSC thermograms.

\subsubsection{Densities}

The measured density was found to be $\left(d_{P K S}\right)_{E}=1.502 \mathrm{~g} \cdot \mathrm{cm}^{-3}(\mathrm{sd}=0.107)$ for PKS Dura consistent withthatreported in references [14] [50] and $\left(d_{P K S}\right)_{E}=1.381 \mathrm{~g} \cdot \mathrm{cm}^{-3}$ $(s d=0.0004)$ for PKS Tenera. As can also be noted from the difference in shell 
thicknesses of Dura and Tenera, this result suggests that genetic crossbreeding influences the density of the PKS material. Using the ROM law yields $\left(d_{P K S}\right)_{R O M}=$ $1.422 / 1.420 \mathrm{~g} \cdot \mathrm{cm}^{-3}$, a result consistent with the experiment on apparent density [14]. More accurate true density measurements of powders, granules, porous materials, can be performed by the use of a test gas (e.g. helium), in gas pycnometers [51] [52].

\subsection{Chemical Constituents Evaluation}

Table 1 presents results of wet chemistry of PKS, for two analyses. Lignin content of PKS appeared to be greater than that of Cellulose and Hemicelluloses. However, the hemicelluloses content obtained here is lower than that presented in the literature [16] [33]. The PKS also contain mineral material in the form of ash that corresponds to the residue obtained after incineration of each dry sample, with MM-NDF fraction being smaller than the MM-ADF. As will be seen below, the MM fraction is consistent with TGA results. Ash is an inorganic part, inert, "useless" and amorphous carbon present in the PKS, a mixture of calcium salts and metal oxides [13] [14]. The mineral matter represents the remaining material after the incineration of $1 \mathrm{~g}$ of each sample of dried PKS at $550^{\circ} \mathrm{C}$ during 6 hours [47]. The chemical composition of the PKS is complex and varies to some extent depending on the source and its age. Hence, it could be difficult to define structural formulas of these mixtures of biopolymers. The derived higher content of Lignin (a group of polyphenolic polymers, a polyphenolic macromolecule, with high molecular weights) justifies the higher concentration of phenols in the PKS pyrolysis liquid [33] and encourages lignin extraction from PKS and its use as 3D printing material [42]. The cellulose of PKS is likely amorphous, since TEM/EDXA shows that most of the PKS material is mainly an amorphous carbon/oxygen phase.

\subsection{Thermal Characteristics}

\subsubsection{DSC}

Figure 7 shows the DSC combined thermograms of CKS and PKS Tenera (obtained from different particle sizes $\leq 0.04 ; 0.05 ; 0.2 ; 0.5 \mu \mathrm{m}$ ). The measured $T_{m}$ and corresponding $\Delta H_{m}$ values for powder specimens with different maximum particle sizes are summarized in Table 2 for PKS and CKS. The exothermic convex peak at around $100^{\circ} \mathrm{C}$ of the thermogram corresponds to the loss of volatiles and/or water. The three endothermic peaks at $230^{\circ} \mathrm{C}-260^{\circ} \mathrm{C}, 300^{\circ} \mathrm{C}$ $350^{\circ} \mathrm{C}$, and $410^{\circ} \mathrm{C}-430^{\circ} \mathrm{C}$ likely correspond to Hemicelluloses, Cellulose and lignin melts respectively. Cellulose is a linear macromolecule; it is therefore expected to reveal melting behavior when heated. On the other hand, the macromolecular chains of cellulose consist of ether bonds of "O", which is a relatively weak chemical bond. That means, the ether bonds can be broken with thermal energies smaller than energies needed to melt them. The outcome is degradation and decomposition of cellulose before total melting of PKS/CKS takes place. The temperatures of melt $T_{m, H O} T_{m, C}$ and $T_{m, L}$ (Table 2) of hemicelluloses, cellulose 
and lignin respectively are consistent with that obtain in previous studies [53] [54]. The enthalpy associated with each of these transitions is readily obtained from the DSC thermogram. The derived thermal conductivity and diffusivity coefficients were found to be $k_{P K S}=306 \mathrm{~mW} \cdot \mathrm{m}^{-1} \cdot \mathrm{K}^{-1}$ and $a_{P K S}=2.06 \mathrm{~cm}^{2} \cdot \mathrm{s}^{-1}$.

\subsubsection{TGA/DTGA}

Figure 8 presents combined TGA and DSC (DSC-TGA) and (Figure 9) the combined TGA-DTGA pyrolysis thermograms, whereas Figure 10 shows the TGA-DTGA oxidation thermograms of CKS and PKS. The descending TGA thermogram curve indicates that a weight loss occurred, for samples degrading with temperature. The TGA weight loss curve shows three distinct weight losses representing each component. The derivative curve also has 3 peaks. This confirms that there are three distinct thermal events taking place in this experiment. Ma et al. [34] reportedonlytwo thermal events. As alsoreported by Suriapparao and Vinu [55] particlesizes and heating rates influence the activation energy, the yield of phenolics and linearhydrocarbonsduringbiomasspyrolysis. The proportion of each component must be consistent, if the product is to provide useful and safe functionalities. The small weight loss of volatiles [34], 6.53\% (for CKS) and $9.37 \%$ (for $\mathrm{PKS}$ ), begins in the range $50^{\circ} \mathrm{C}-75^{\circ} \mathrm{C}$ mark and evolves up to $135^{\circ} \mathrm{C}$ depending on the powder fineness. Then, the PKS and CKS materials seem to remain thermally stable up to a temperature of about $200^{\circ} \mathrm{C}$. The PKS decomposes in two steps, first rapidly, with the degradation of hemicelluloses and cellulose, and then slowly as the last remaining lignin material decomposes. However, this order of thermal events could specific to each biomass. Table 2 gives an outlook of the derived thermal transition values and properties, whereas Table 3 contains the deduced chemical constituent of PKS and CKS with more precision obtained from Air TGA results given in Figure 10. It is found that the enthalpy of PKS/CKS microparticles reached $66.25 / 62.09 \mathrm{~J} \cdot \mathrm{g}^{-1}$. Therefore, these materials could be used as a wall material of phase change materials [56].

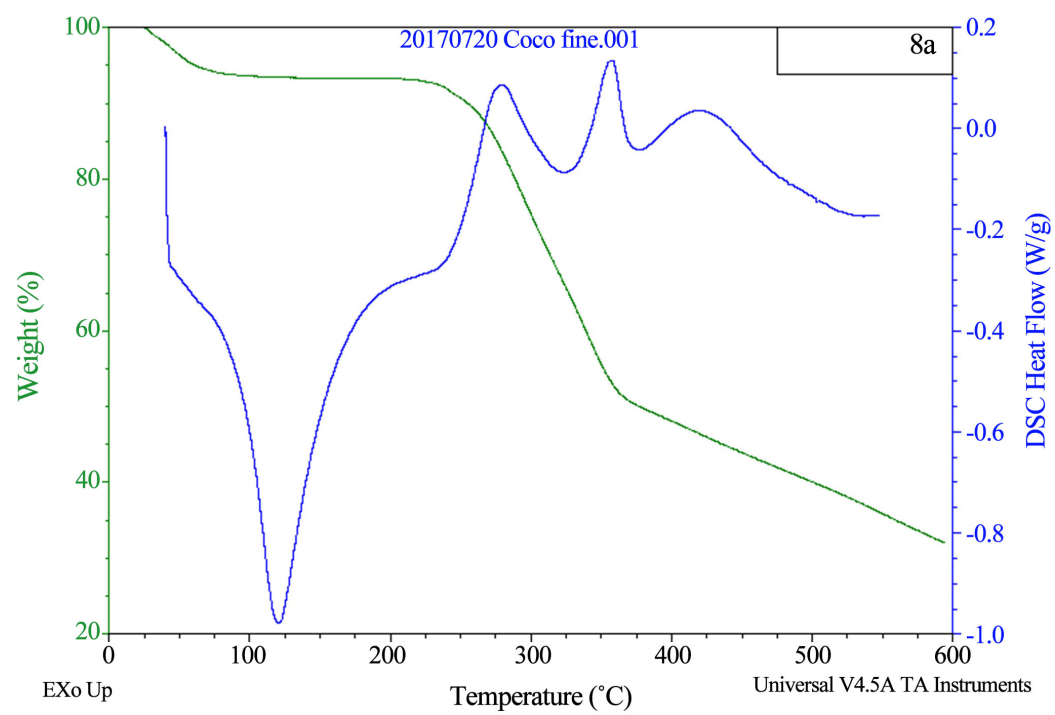




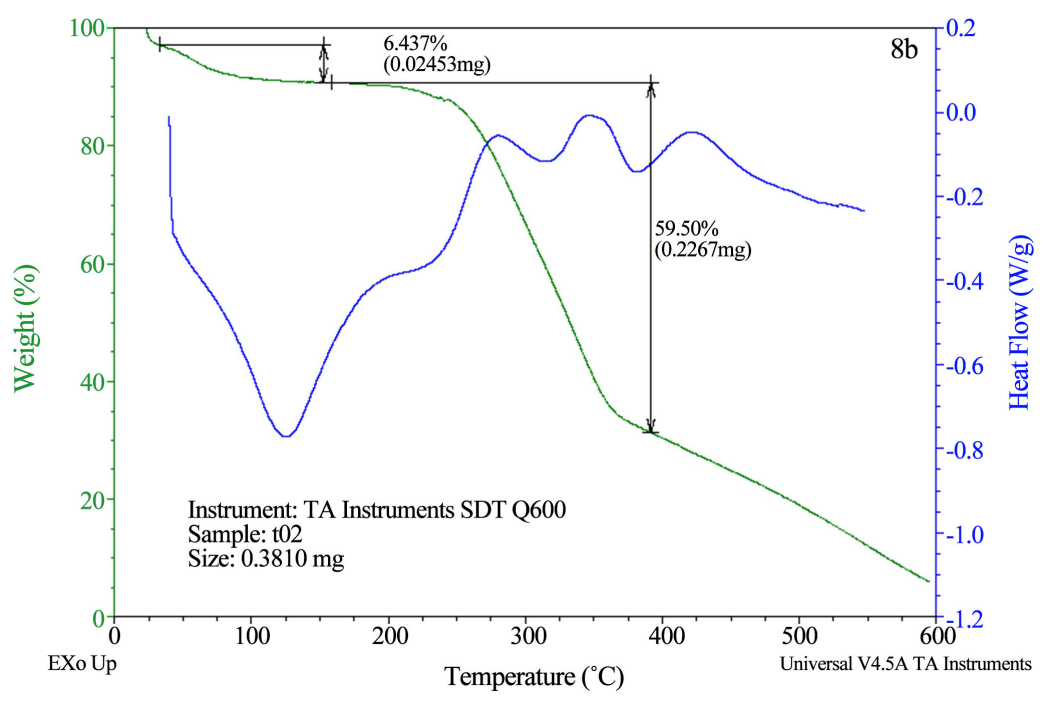

Figure 8. DSC-TGA pyrolysis thermograms (a) for CKS (b) for PKS.

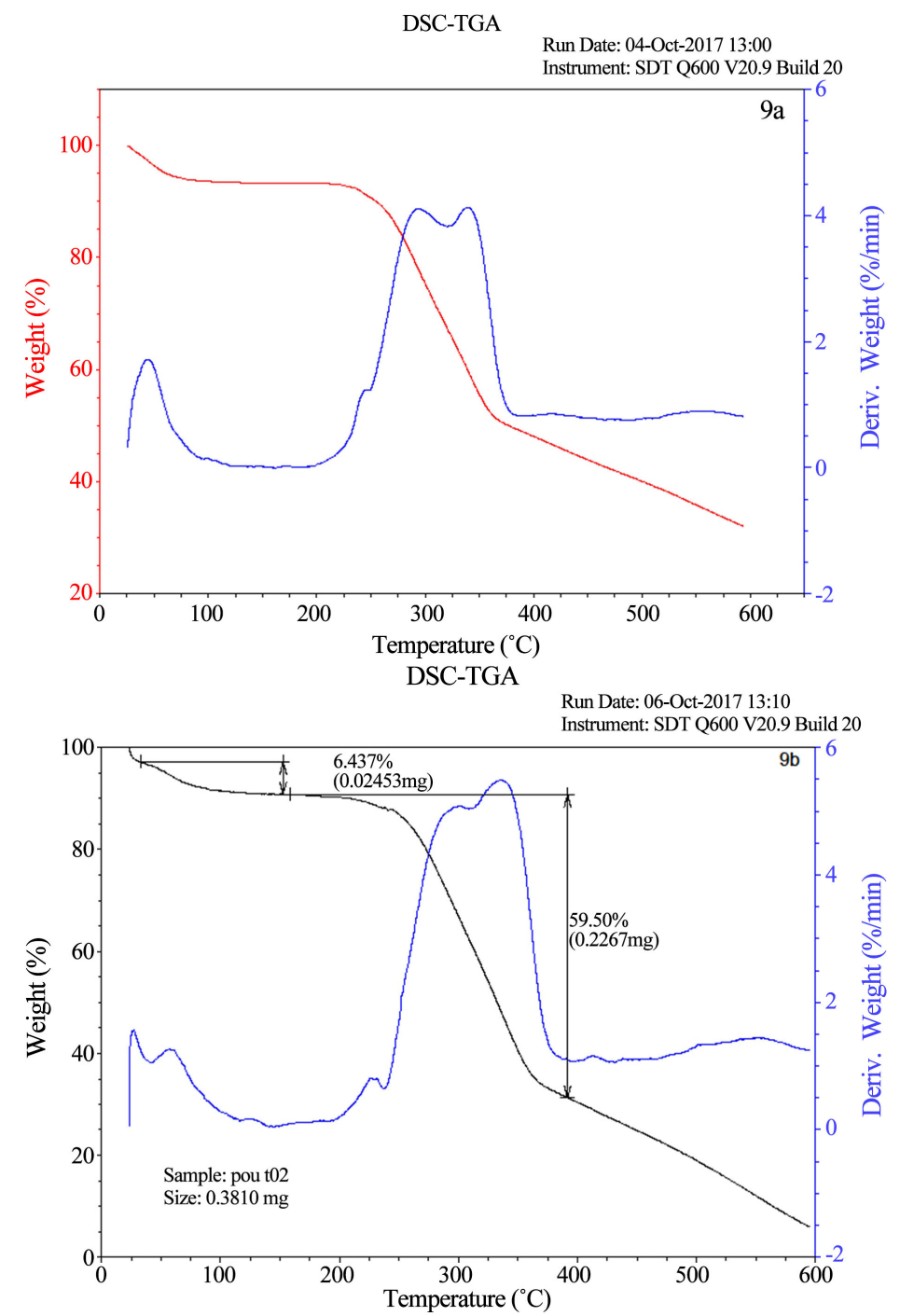

Figure 9. TGA-DTGA pyrolysis thermograms (a) for CKS (b) for PKS. 


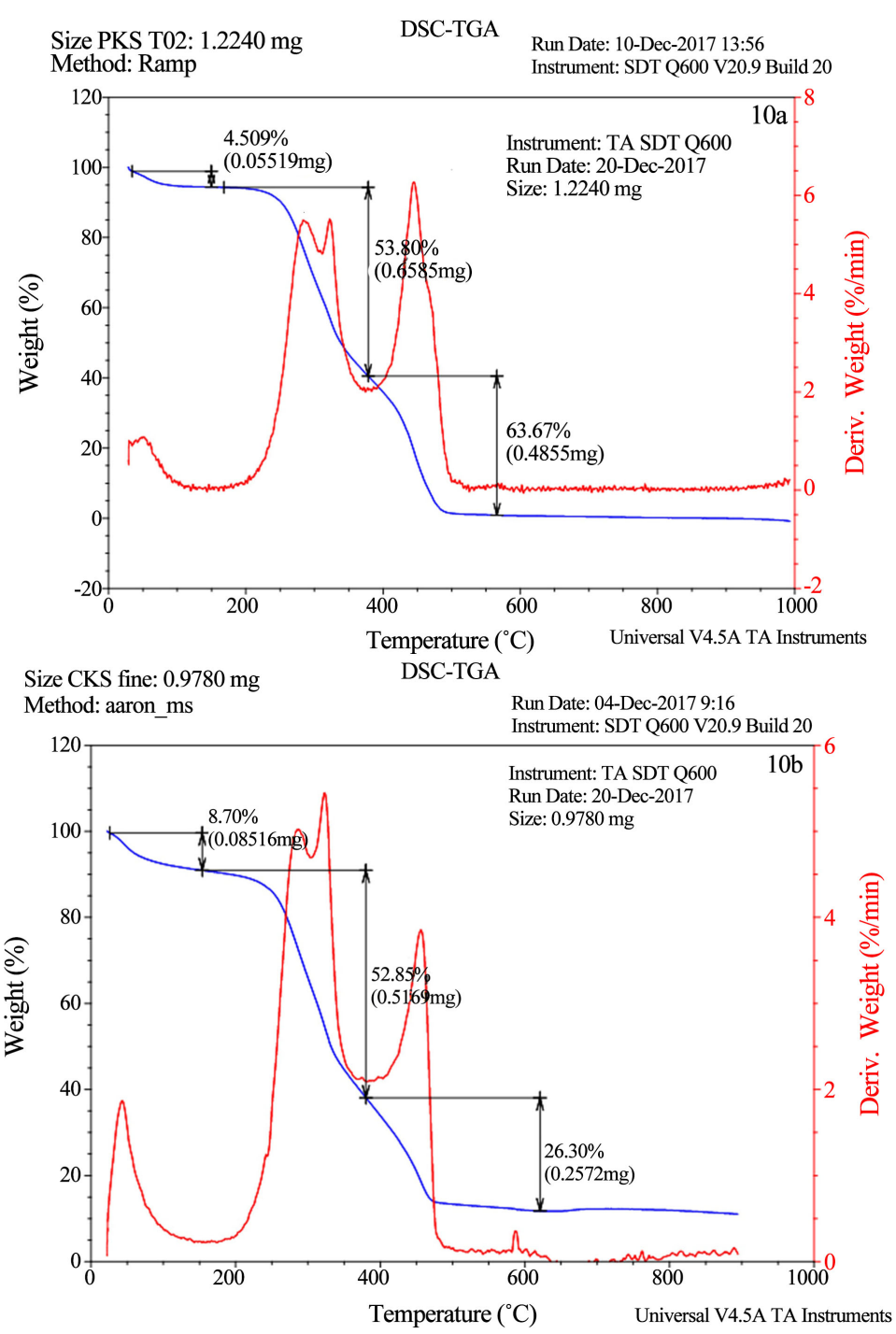

Figure 10. TGA-DTGA oxidation thermograms (a) PKS, (b) CKS.

Table 1. Wet Chemistry of PKS; N \& A stands for NDF and ADF analysis.

\begin{tabular}{ccccc}
\hline Analysis $\mathrm{N}^{\circ}$ & \multicolumn{4}{c}{ Chemical compounds $(w \%)$} \\
\hline & $\boldsymbol{w}_{\boldsymbol{L}}$ & $\boldsymbol{w}_{C}$ & $\boldsymbol{w}_{H C}$ & $\boldsymbol{W}_{\boldsymbol{M M n} n} / \boldsymbol{w}_{\boldsymbol{M M a}}$ \\
PKS1 & 44.20 & 35.20 & $18.79 / 13.82$ & $1.81 / 6.79$ \\
PKS2 & 43.76 & 34.04 & $20.77 / 15.41$ & $1.43 / 6.78$ \\
\hline
\end{tabular}

Table 2. DSC and TGA thermal characteristics of PKS and CKS.

\begin{tabular}{|c|c|c|c|c|c|}
\hline \multirow[t]{2}{*}{ Sample } & \multicolumn{4}{|c|}{ Temperatures $\left({ }^{\circ} \mathrm{C}\right) /$ Enthalpies $(\mathrm{J} / \mathrm{g})$} & Step-Height at $\mathrm{Tg} / \mathrm{Thermal}$ Con- \\
\hline & $T_{g}$ & $T_{m, H d} \Delta H_{m, H C}$ & $T_{m, d} \Delta_{H m, C}$ & $T_{m, L} / \Delta H_{m, L}$ & $\Delta C_{p}\left(\mathrm{~J} \cdot \mathrm{g}^{-1} \cdot{ }^{\circ} \mathrm{C}^{-1}\right) / k\left(\mathrm{~mW} \cdot \mathrm{m}^{-1} \cdot \mathrm{K}^{-1}\right)$ \\
\hline PKS & 241.66 & $264.88 / 48.85$ & $343.77 / 28.33$ & $423.58 / 27.33$ & $0.106 / 306$ \\
\hline CKS & 246.39 & $274.28 / 62.09$ & $357.3 / 23.47$ & $423.23 / 37.74$ & $0.086 /-$ \\
\hline PKS [33] & - & 295/- & $330 /-$ & $515 /-$ & - \\
\hline
\end{tabular}


Table 3. TGA-DTGA deduced chemical contents of PKS and CKS.

\begin{tabular}{ccccc}
\hline Material & \multicolumn{4}{c}{ Chemical compounds $(w \%)$} \\
\hline PKS & $\boldsymbol{w}_{\boldsymbol{L}}$ & $\boldsymbol{w}_{C}+\boldsymbol{w}_{H C}$ & Ash & volatiles \\
CKS & 39.67 & 53.80 & 2.021 & $4.509-9.63$ \\
CKS $[43]$ & 26.30 & 52.85 & 11.091 & $6.53-8.70$ \\
\hline
\end{tabular}

\section{Conclusion}

Palm Kernel Shells (PKS) have been assessed as a potential source of raw materials for various engineering applications in this paper. First, the ultrastructure of PKS has been revealed using SEM/EDS and TEM/EDXA techniques. Micrographs observations show that the PKS microstructure is not homogeneous as commonly expected. Morphologically, PKS appears similar to CKS. Indeed, PKS particles have very clear plant cell/tissue structures, with micro/nanopores that make this material a suitable candidate for membrane filtration, for instance. From the spectrum of EDS, the sample contains carbon and oxygen identified as main elements, and silicon in a small proportion. Some rock-like particles were occasionally observed and EDS analysis showed they mainly contain silicon. However, $\mathrm{Al}, \mathrm{K}, \mathrm{Ca}, \mathrm{Fe}, \mathrm{Mg}, \mathrm{C}$ and $\mathrm{O}$ were also detected in the rock-like particles. Again, X-ray microanalysis performed on TEM sample nano-locations is consistent with that performed on SEM sample micro-locations. The detection of $\mathrm{Ca}, \mathrm{P}, \mathrm{Mg}$ and $\mathrm{O}$, justifies the empirical use of PKS in sanitation and purification. Moreover, wet chemistry by means of Van Soest (NDF and ADF) has enabled the quantification of the amount of hemicelluloses, cellulose and lignin as major chemicals, with higher lignin content. Additionally, the relevant thermal characteristics were studied using DSC and TGA. No thermal reversibility was observed above $300^{\circ} \mathrm{C}$. Thermal Transition phases as observed from DSC and TG/DTG thermograms confirm the composite nature of PKS/CKS with 3 major thermal events that are related to melts of main PKS and CKS chemicals, precisely hemicelluloses, cellulose and lignin respectively. Thermal characteristics and phase transition temperatures of PKS/CKS that were assessed in this study are consistent with their chemical composition. Nevertheless the necessity arises here to clarify events priority during biomass thermal degradation. The enthalpy of PKS/CKS microparticles reached $66.25 / 62.09 \mathrm{~J} \cdot \mathrm{g}^{-1}$. Therefore, these materials could be used as a wall material of phase change materials. Further investigations could also focus on the reinforcement of polymer ceramics with $\mathrm{PKS} / \mathrm{CKS}$, as a novel use for $3 \mathrm{D}$ printing biomaterials and membrane filtration materials.

\section{Acknowledgements}

We acknowledge Dr. Craig Bennett and Dr. Haixin Zhang for their support in insightful microstructural analyses of the samples, and Professor Awitor and 
Thibault Peudon for their valuable support during laboratory chemical analyses carried out at the IUT, the University of Clermont-Ferrand II (France). We are also grateful to Dr. Ngando, Senior Researcher and Director of IRAD Mbongo for providing us with the PKS Dura materials. This work has been supported by the NSCC's General Research Fund 2018/2019, and the organizations (CFI, AIF and other partners) funding the Facilities for Materials Characterization, managed by the Clean Technologies Research Institute at Acadia University.

\section{Conflicts of Interest}

The authors declare no conflicts of interest regarding the publication of this paper.

\section{References}

[1] Mo, K.H., Alengaram, U.J. and Jumaat, M.Z. (2014) A Review on the Use of Agriculture Waste Material as Lightweight Aggregate for Reinforced Concrete Structural Members. Advances in Materials Science, 2014, Article ID: 365197. https://doi.org/10.1155/2014/365197

[2] Badr, K.H., Othman, Z. and Ahmad, S.H. (2004) Rigid Polyurethane Foams from Oil Palm Resources. Journal of Materials Science, 39, 5541-5542. https://doi.org/10.1023/B:JMSC.0000039282.86374.fC

[3] Oti, O.P., Nwaigwe, K.N. and Okereke, N.A.A. (2017) Assessment of Palm Kernel Shell as a Composite Aggregate in Concrete. Agricultural Engineering International: CIGR Journal, 19, 34-41.

[4] Eman Evina, H. (2003) Oil Palm Fruit (Elaeis guineensis Jacq. Var. Dura) Growing part II: Settlement and Growth of the Seed. Université de Yaoundé I, Yaoundé.

[5] Fashina, A.B., Durodola, O.S. and Hammed, I.A. (2017) Development and Performance Evaluation of an Oil Palm Fruit Digester. Bioprocess Engineering, 1, 49-53.

[6] WFO (2012) Food Outlook May 2012. http://www.fao.org/fileadmin

[7] Pang, C.H., Gaddipatti, S., Tucker, G., et al. (2014) Relationship between Thermal Behaviour of Lignocellulosic Components and Properties of Biomass. Bioresource Technology, 172, 312-320. https://doi.org/10.1016/j.biortech.2014.09.042

[8] Béakou, A. and Ntenga, R. (2011) Structure, Morphology and Mechanical Properties of Rhectophyllum camerunense (RC) Plant Fiber. Part II: Computational Homogenization of the Anisotropic Elastic Properties. Computational Materials Science, 50, 1550-1558. https://doi.org/10.1016/j.commatsci.2010.12.013

[9] Lopez, M.I., Chen, P.-Y., McKittrick, J. and Meyers, M.A. (2014) Comparison on the Structural and Mechanical Properties of Untreated Deproteinized Nacre. In: McKittrick, J. and Narayan, R., Eds., Advances in Bioceramics and Biotechnologies II, John Wiley \& Sons, Hoboken, 37-45.

[10] Khalil, H.P.S.A., Yusra, A.F.I., Bhat, A.H. and Jawaid, M. (2010) Cell Wall Ultrastructure, Anatom, Lignin Distribution, and Chemical Composition of Malaysian Cultivated Kenaf Fiber. Industrial Crops and Products, 31, 113-121. https://doi.org/10.1016/j.indcrop.2009.09.008

[11] Herawan, S.G., Hadi, M.S., Ayob, M.R. and Putra, A. (2013) Characterization of Activated Carbons from Oil-Palm Shell by $\mathrm{CO}_{2}$ Activation with No Holding Carbonization Temperature. The Scientific World Journal, 2013, 1-6. 
https://doi.org/10.1155/2013/624865

[12] Adinata, D., Wan Daud, W.M.A. and Kheireddine Aroua, M. (2007) Preparation and Characterization of Activated Carbon from Palm Shell by Chemical Activation with $\mathrm{K}_{2} \mathrm{CO}_{3}$. Bioresource Technology, 98, 145-149.

https://doi.org/10.1016/j.biortech.2005.11.006

[13] Guo, J. and Lua, A.C. (2003) Surface Functional Groups on Oil-Palm-Shell Adsorbents Prepared by $\mathrm{H}_{3} \mathrm{PO}_{4}$ and $\mathrm{KOH}$ Activation and Their Effects on Adsoptive Capacity. Chemical Engineering Research and Design, 81, 585-590. https://doi.org/10.1205/026387603765444537

[14] Guo, J. and Lua, A.C. (2000) Preparation and Characterization of Adsorbents from Oil Palm Fruit Solid Wastes. Journal of Oil Palm Research, 12, 64-70.

[15] Zhao, X.Q., Song, Z.L., Liu, H.Z., et al. (2010) Microwave Pyrolysis of Corn Stalk Bale: A Promising Method for Direct Utilization of Large-Sized Biomass and Syngas Production. Journal of Analytical and Applied Pyrolysis, 89, 87-94. https://doi.org/10.1016/j.jaap.2010.06.001

[16] Salema, A.A. and Ani, F.N. (2012) Microwave-Assisted Pyrolysis of Oil Palm Shell Biomass Using an Overhead Stirrer. Journal of Analytical and Applied Pyrolysis, 96, 162-172. https://doi.org/10.1016/j.jaap.2012.03.018

[17] Ani, F.N. and Salema, A.A. (2008) Pyrolisis of Oil Palm Biomass Using Palm Shell Char as Microwave Absorber. Journal of Oil Palm Research, 24, 1497-1512.

[18] Kawser, J. and Farid Nash, A. (2000) Oil Palm Shell as a Source of Phenol. Journal of Oil Palm Research, 12, 84-94.

[19] Gardziella, A., Pilato, L.A. and Knop, A. (2000) Phenolic Resins: Chemistry, Applications, Standardization, Safety and Ecology. 2nd Edition, Springer, Berlin. https://doi.org/10.1007/978-3-662-04101-7

[20] Sabzoi, N., Yong, E.K., Jayakumar, N.S., et al. (2015) Optimisation Study for Catalytic Hydrolysis of Oil Palm Shell Using Response Surface Methodology. Journal of Oil Palm Research, 27, 339-351.

[21] Kupaei, R.H., Alengaram, U.J. and Jumaat, M.Z. (2014) The Effect of Different Parameters on the Development of Compressive Strength of Oil Palm Shell Geopolymer Concrete. The Scientific World Journal, 2014, Article ID: 898536.

[22] Yew, M.K., Bin Mahmud, H., Ang, B.C. and Yew, M.C. (2015) Effects of Low Volume Fraction of Polyvinyl Alcohol Fibers on the Mechanical Properties of Oil Palm Shell Lightweight Concrete. Advances in Materials Science and Engineering, 2015, Article ID: 425236. https://doi.org/10.1155/2015/425236

[23] Che Muda, Z.A., Sharif, S.F., Bte Mohd Sideka, L. and Farhan, N.S. (2013) Impact Resistance of Oil Palm Shells Lightweight Concrete Slab with Bamboo Fibers. International Journal of Scientific and Engineering Research, 4, 21-38.

[24] Liu, M.Y.J., Chua, C.P., Alengaram, U.J. and Jumaat, M.Z. (2014) Utilization of Palm Oil Fuel Ash as Binder in Lightweight Oil Palm Shell Geopolymer Concrete. Advances in Materials Science and Engineering, 2014, Article ID: 610274. https://doi.org/10.1155/2014/610274

[25] Ofuyatan, T., Olutoge, F.A. and Olowofoyeku, A. (2015) Durability Properties of Palm Oil Fuel Ash Self Compacting Concrete. Engineering, Technology \& Applied Science Research, 5, 753-756.

[26] Fono-Tamo, R.S., Idowu, O.O. and Koya, F.O. (2014) Development of Pulverized Palm Kernel Shells Based Particleboard. International Journal of Mechanical and Materials Engineering, 3, 54-61. https://doi.org/10.14355/ijmme.2014.0303.01 
[27] Magniont, C. and Escadeillas, G. (2017) Chemical Composition of Bio-Aggregates and Their Interactions with Mineral Binders. In: Amziane, S. and Collet, F., Eds., Bio-Aggregates Based Building Materials. State-of-the-Art Report, Springer, Berlin, 1-37. https://doi.org/10.1007/978-94-024-1031-0_1

[28] Youssefian, S. and Rahbar, N. (2015) Molecular Origin of Strength and Stiffness in Bamboo Fibrils. Scientific Reports, 5, Article No. 11116. https://doi.org/10.1038/srep11116

[29] Singh, K., Risse, M., Das, K.C. and Worley, J. (2009) Determination of Composition of Cellulose and Lignin Mixtures Using Thermogravimetric Analysis. Journal of Energy Resources Technology, 131, 219-226. https://doi.org/10.1115/1.3120349

[30] Liu, J., Qu, W., Xie, Y., et al. (2017) Thermal Conductivity and Annealing Effect on Structure of Lignin-Based Microscale Carbon Fibers. Carbon, 121, 35-47. https://doi.org/10.1016/j.carbon.2017.05.066

[31] Brebu, M. and Vasile, C. (2010) Thermal Degradation of Lignin-A Review. Cellulose Chemistry and Technology, 44, 353-363.

[32] Hatakeyama, H., Kosugi, R. and Hatakeyama, T. (2008) Thermal Properties of Lignin and Molasses-Based Polyurethane Foams. Journal of Thermal Analysis and Calorimetry, 92, 419-424. https://doi.org/10.1007/s10973-007-8963-1

[33] Ninduangdee, P., Kuprianova, V.I., Young Cha, E., et al. (2015) Thermogravimetric Studies of Oil Palm Empty Fruit Bunch and Palm Kernel Shell: TG/DTG Analysis and Modeling. Energy Procedia, 79, 453-458. https://doi.org/10.1016/j.egypro.2015.11.518

[34] Ma, Z., Chen, D., Gu, J., et al. (2015) Determination of Pyrolysis Characteristics and Kinetics of Palm Kernel Shell Using TGA-FTIR and Model-Free Integral Methods. Energy Conversion and Management, 89, 251-259. https://doi.org/10.1016/j.enconman.2014.09.074

[35] Yu, X.C., Sun, D.L., Sun, D.B., et al. (2010) Basic Properties of Woodceramics Made from Bamboo Powder and Epoxy Resin. Wood Science and Technology, 46, 23-31. https://doi.org/10.1007/s00226-010-0390-y

[36] Novitskaya, E., Ribero Vairo, M.S., Kiang, J., et al. (2014) Reinforcing Structures in Avian Wing Bones. Ceramic Transactions, 247, 47-56. https://doi.org/10.1002/9781118771587.ch5

[37] Carlborn, K. and Matuana, L.M. (2005) Composite Materials Manufactured from Wood Particles Modified through a Reactive Extrusion Process. Polymer Composites, 26, 534-541. https://doi.org/10.1002/pc.20122

[38] Balan, A.K., Mottakkunnu Parambil, S., Vakyath, S., et al. (2017) Coconut Shell Powder Reinforced Thermoplastic Polyurethane/Natural Rubber Blend-Composites: Effect of Silane Coupling Agents on the Mechanical and Thermal Properties of the Composites. Journal of Materials Science, 52, 6712-6725. https://doi.org/10.1007/s10853-017-0907-y

[39] Avella, M., La Rota, G., Martuscelli, E., Raimo, M., Sadocco, P., Elegir, G. and Riva, R. (2000) PHBV and Wheat Straw Fibre Composites: Thermal, Mechanical Properties and Biodegradation. Journal of Materials Science, 5, 829-836. https://doi.org/10.1023/A:1004773603516

[40] Lee, J., Shim, M. and Kim, S. (2001) Thermal Degradation of Epoxy/Natural Zeolite Composites. Journal of Materials Science, 6, 4405-4409. https://doi.org/10.1023/A:1017918400130

[41] Valentin, T.M., Leggett, S.E., Chen, P.-Y., et al. (2017) Stereolithographic Printing 
of Ionically-Crosslinked Alginate Hydrogels for Degradable Biomaterials and Microfluidics. Lab on a Chip, 17, 3474-3488. https://doi.org/10.1039/C7LC00694B

[42] Nguyen, N.A., Bowland, C.C. and Naskar, A.K. (2018) A General Method to Improve 3D-Printability and Inter-Layer Adhesion in Lignin-Based Composites. Applied Materials Today, 12, 138-152. https://doi.org/10.1016/j.apmt.2018.03.009

[43] Liyanage, C.D., Pieris, M. and Mevan, P. (2015) A Physico-Chemical Analysis of Coconut Shell Powder. Procedia Chemistry, 16, 222-228. https://doi.org/10.1016/j.proche.2015.12.045

[44] Incropera, F., DeWitt, D.P., Bergman, T.L. and Lavine, A.S. (2006) Fundamentals of Heat and Mass Transfer. 6th Edition, John Wiley \& Sons, Hoboken.

[45] Van Soest, P.J. (1969) Composition, Fiber Quality and Nutritive Value of Forages. Advances in Chemistry, 95, 262-278.

[46] Van Soest, P.J. and Robertson, J.B. (1985) Analysis of Forages and Fibrous Foods: A Laboratory Manual for Animal Science. Cornell University Ithaca, New York.

[47] Boultifat, L. (2008) Evaluation de la contribution spécifique des fractions soluble et insoluble de sous-produits de l'agronomie saharienne à la méthanogénèse ruminale d'ovins. Université de Mentouri de Constantine.

[48] Wang, Z., Yang, X., Zhou, Y. and Liu, C. (2013) Mechanical and Thermal Properties of Polyurethane Films from Peroxy-Acid Wheat Straw Lignin. BioResources, 8, 3833-3843. https://doi.org/10.15376/biores.8.3.3833-3843

[49] Edmund, C.O., Christopher, M.S. and Pascal, D.K. (2014) Characterization of Palm Kernel Shell for Materials Reinforcement and Water Treatment. Journal of Chemical Engineering and Materials Science, 5, 1-6. https://doi.org/10.5897/JCEMS2014.0172

[50] Guo, J. and Lua, A.C. (2003) Textural and Chemical Properties of Adsorbent Prepared from Palm Shell by Phosphoric Acid Activation. Materials Chemistry and Physics, 80, 114-119. https://doi.org/10.1016/S0254-0584(02)00383-8

[51] DIN 51913 (1993) Testing of Carbon Materials-Determination of Density by Gas Pycnometer (Volumetric) Using Helium as the Measuring Gas.

[52] ASTM B923-02 (2008) Standard Test Method for Metal Powder Skeletal Density by Helium or Nitrogen Pycnometry.

[53] Saba, N., Jawaid, M. and Sultan, M.T.H. (2017) Thermal Properties of Oil Palm Biomass Based Composites. In: Jawaid, M., Md Tahir, P. and Saba, N., Eds., Lignocellulosic Fibre and Biomass-Based Composite Materials, Woodhead Publishing, Sawston, 95-122.

[54] Nomanbhay, S.M. and Palanisamy, K. (2005) Removal of Heavy Metal from Industrial Wastewater Using Chitosan Coated Oil Palm Shell Charcoal. Electronic Journal of Biotechnology, 8, 43-54. https://doi.org/10.2225/vol8-issue1-fulltext-7

[55] Suriapparao, D.V. and Vinu, R. (2018) Effects of Biomass Particle Size on Slow Pyrolysis Kinetics and Fast Pyrolysis Product Distribution. Waste and Biomass Valorization, 9, 465-477. https://doi.org/10.1007/s12649-016-9815-7

[56] Huang, Z., Yu, X., Li, W. and Liu, S. (2015) Preparation of Urea-Formaldehyde Paraffin Microcapsules Modified by Carboxymethyl Cellulose as a Potential Phase Change Material. Journal of Forest Research, 26, 253-260.

https://doi.org/10.1007/s11676-015-0027-y 